\title{
Características químicas e sensoriais do leite de cabras Moxotó alimentadas com silagem de maniçoba
}

\section{Roberto Germano Costa ${ }^{1}$, Ítala Viviane Ubaldo Mesquita ${ }^{2}$, Rita de Cássia Ramos do Egypto Queiroga ${ }^{3}$, Ariosvaldo Nunes de Medeiros ${ }^{4}$, Francisco Fernando Ramos de Carvalho ${ }^{5}$, Edvaldo Mesquita Beltrão Filho ${ }^{6}$}

\footnotetext{
${ }^{1}$ Departamento de Agropecuária/CFT/UFPB, Bananeiras - PB.

2 Programa de Pós-Graduação em Zootecnia/PPGZ/UFPB, Areia - PB.

${ }^{3}$ Departamento de Nutrição/CCS/UFPB, João Pessoa - PB.

${ }^{4}$ Departamento de Zootecnia/CCA/UFPB, Areia - PB.

${ }^{5}$ Departamento de Zootecnia/UFRPE, Recife - PE.

${ }^{6}$ Programa de Doutorado Integrado em Zootecnia/PDIZ/UFPB, Areia - PB.
}

RESUMO - Avaliaram-se os efeitos da utilização de silagem de maniçoba (Manihot glaziovii Muell. Arg.) nas relações volumoso:concentrado 30:70; 40:60; 50:50 e 60:40\% sobre a composição do leite, o perfil de ácidos graxos e as características sensoriais do leite de cabras Moxotó. Utilizaram-se oito cabras multíparas com aproximadamente 60 dias pós-parto, pesando em média $44 \mathrm{~kg}$, em um delineamento quadrado latino duplo $4 \times 4$, com quatro tratamentos, quatro períodos e quatro animais. Cada período teve duração de 15 dias: dez de adaptação dos animais às dietas e cinco de coleta do leite. Não foi observado efeito das dietas na composição química do leite, que apresentou valores médios de proteína (3,79\%), gordura (3,97 \%), lactose (4,66 \%), extrato seco total $(13,12 \%)$, densidade $(1,033)$ e acidez $\left(19^{\circ} \mathrm{D}\right)$. O fornecimento de silagem de maniçoba influenciou de forma linear crescente as concentrações de ácido mirístico (C14:0), que apresentaram valores de 6,15 a 7,85\%, e de forma decrescente os teores de ácido linolênico (C18:3), cujos valores médios foram de 2,13 a 0,76\% conforme aumentaram os níveis de silagem na dieta. Os resultados da ADQ (análise descritiva quantitativa) indicam que a utilização de silagem de maniçoba em dieta para cabras não confere mudanças sensoriais perceptíveis no leite. A inclusão de silagem de maniçoba na alimentação de cabras leiteiras em níveis de até $60 \%$ da dieta não altera a composição e as características sensoriais do leite.

Palavras-chave: ácidos graxos, análise sensorial, composição do leite de cabra, Manihot glaziovii, volumoso:concentrado

\section{Sensorial and chemical characteristics of the milk of Moxotó goats fed with maniçoba silage}

\begin{abstract}
The objective of this work was to evaluate the effects of the use of maniçoba silage (Manihot glaziovii Muell. Arg.) in different forage:concentrate ratio (30:70; 40:60; 50:50 and 60:40\%) in milk composition, fatty acids profile and sensorial characteristics of Moxotó dairy goat milk. Eight multiparus goats were used, with approximately 60 days postpartum and about $44 \mathrm{~kg}$ on average, in a $4 \times 4$ Latin square design, with four treatments, four periods and 4 animals. Each period lasted 15 days : 10 of adaptation of the animals to the diets and 5 of milk collection. No effect of the diets was observed on milk chemical composition, which showed mean values of protein (3.79\%), fat (3.97\%), lactose (4.66\%), total dry extract $(13.12 \%)$, density $(1.033)$ and acidity $\left(19^{\circ} \mathrm{D}\right)$. A positive linear effect was observe for the miristic acid (C14:0), with mean values from 6.15 to $7.85 \%$, and a negative linear effect was observed for the linolenic acid (C18:3), with mean values from 2.13 to $0.76 \%$, due to the increase of silage levels in the diet. The results of ADQ (quantitative and descriptive analyses) show that the use of maniçoba silage in goats diet did not cause sensorial perceptible changes in the milk. The maniçoba silage inclusion in feeding of milk goat up to the level of $60 \%$ in the diet did not change the composition and sensorial characteristics of Moxotó breed goat milk.
\end{abstract}

Key Words: fatty acids, goat milk composition, Manihot glaziovii, forage:concentrate, sensory analysis

\section{Introdução}

O leite caprino apresenta elevado valor biológico e qualidades nutricionais que superam em vários aspectos o leite bovino, pela maior digestibilidade e pelas características dietéticas; por isso, tem sido bastante recomendado para alimentação de crianças, adultos e idosos sensíveis ou alérgicos ao leite de vaca (Chandan et al., 1992; Haenlein, 2004; Park et al., 2007). 
Fatores genéticos, fisiológicos e ambientais são considerados premissas na composição química e nas propriedades do leite. Entre esses fatores, a alimentação tem sido fundamental na manipulação dos componentes do leite, principalmente quanto ao perfil lipídico, que afeta diretamente seu sabor e odor. A dieta à base de pastagens, em razão das substâncias presentes nas forragens com propriedades odoríferas, pode modificar a composição química e as propriedades sensoriais do leite, relacionadas à composição em ácidos graxos e enzimas do leite (Coulon \& Priolo, 2002).

Produtores rurais do semi-árido utilizam a pastagem nativa como única fonte de alimentação dos rebanhos, no entanto, nos períodos de estiagem, a capacidade de suporte da caatinga é limitada e ocasiona baixos índices produtivos por não atender às exigências mínimas dos animais. A vegetação nativa dos sertões nordestinos possui grande biodiversidade em seu extrato herbáceo. Nesse contexto, a maniçoba (Manihot glaziovii Muel Arg.) constitui alternativa alimentar para a produção animal da região, principalmente no período seco, pela sua adaptabilidade às condições semi-áridas, pelo elevado valor nutritivo e pela alta palatabilidade.

A disponibilidade de alimentos para os rebanhos nos períodos críticos constitui um dos maiores entraves para o fortalecimento da cadeia produtiva da caprinocultura, em virtude do baixo desempenho dos animais, decorrente da falta de produtos no mercado. A utilização de reservas estratégicas para os rebanhos em períodos de estiagem pode ser uma alternativa viável para sucesso dos sistemas de produção pecuária, inclusive a caprinocultura, no semiárido nordestino (Silva \& Medeiros, 2003).

Entre as possíveis práticas de conservação de volumosos, a ensilagem pode contribuir para melhorar a alimentação e elevar a eficiência produtiva do rebanho. Todavia, pesquisas são necessárias para se obter informações sobre a utilização de silagem de maniçoba na alimentação animal e estudar possíveis influências sobre a composição química e as características sensoriais do leite.

A alimentação fornecida aos animais é fator determinante da produção e composição do leite. Inúmeros experimentos têm sido realizados com o propósito de adequar níveis de nutrientes capazes de assegurar as exigências de mantença e os índices de produção pretendidos. Ainda são poucos os trabalhos realizados com maniçoba na alimentação animal, por isso, não são encontrados dados que estabeleçam níveis de participação e combinação com concentrado em dietas para caprinos leiteiros, bem como seus efeitos nas características do leite.

Este trabalho foi realizado com o objetivo de avaliar o efeito do fornecimento de silagem de maniçoba (Manihot glaziovii Muell Arg.) na composição química, no perfil de ácidos graxos e nas características sensoriais do leite de cabras Moxotó.

\section{Material e Métodos}

O experimento foi realizado na Unidade de Pesquisa em Pequenos Ruminantes da Estação Experimental de São João do Cariri, pertencente ao Centro de Ciências Agrárias da Universidade Federal da Paraíba, em São João do Cariri, PB. Foram utilizadas oito cabras Moxotó de 2 2 e 3 a crias, com mesma época de parição, mantidas em confinamento em galpão coberto, com baias individuais de tela nas dimensões $2 \times 2 \mathrm{~m}$, piso de chão batido, providas de comedouro e bebedouro.

O delineamento experimental utilizado foi em quadrado latino $4 \times 4$, composto de quatro animais, quatro períodos e quatro níveis de silagem de maniçoba na ração. Foram utilizados dois quadrados simultâneos. O experimento constou de quatro períodos de 15 dias, os dez primeiros para adaptação dos animais às dietas experimentais e os cinco dias seguintes para coleta de amostras do leite.

Os tratamentos consistiram de dietas contendo silagem de maniçoba como volumoso exclusivo. A silagem foi confeccionada com ramas de maniçoba (folhas + hastes de até 1,0 cm de diâmetro) colhidas em áreas cultivadas e mantidas armazenadas durante 6 meses até o início do experimento. As plantas estavam em estágio vegetativo de floração e início de frutificação e, após o corte, foram expostas ao ar livre durante 4 horas. Depois do pré-murchamento, o material foi triturado em máquina forrageira e compactado, por pisoteio humano, em bombonas plásticas e metálicas.

A silagem foi misturada à ração nas proporções de 30:70, 40:60, 50:50 ou 60:40 volumoso:concentrado, no momento do fornecimento aos animais, duas vezes ao dia, logo após as ordenhas (em torno de 8 h e 17 h). Para garantir consumo ad libitum, a dieta foi fornecida em quantidade suficiente para proporcionar em torno de $20 \%$ de sobras. A água também foi fornecida ad libitum e o consumo foi quantificado diariamente.

As dietas foram formuladas segundo recomendações do AFRC (1998) para atender às exigências nutricionais de cabras em lactação com produção de 2 kg/cabra/dia e $4 \%$ de gordura de leite (Tabelas 1 e 2). As amostras dos alimentos foram processadas e analisadas no Laboratório de Nutrição Animal do Departamento de Zootecnia da UFPB para determinação dos teores de matéria seca (MS), proteína bruta (PB), fibra em detergente neutro (FDN), fibra em detergente ácido (FDA), matéria mineral (MM), matéria orgânica (MO) e extrato etéreo (EE), conforme metodologia descrita por Silva (2002). Os carboidratos totais (CT) foram obtidos pela 
equação: 100 - (\% PB + \% EE + MM\%), enquanto os carboidratos não-fibrosos (CNF), pela diferença entre CT e FDN (Sniffen et al., 1992).

O leite da produção da manhã foi acondicionado em ambiente refrigerado para que, em seguida, fosse misturado ao leite da ordenha da tarde para obtenção de uma amostra composta individual por dia, proporcional à produção de cada ordenha. Do leite ordenhado por animal, retirou-se uma alíquota de $200 \mathrm{~mL}$ para as análises físico-químicas. Para a análise do perfil de ácidos graxos, coletou-se uma alíquota de $100 \mathrm{~mL}$ por meio de uma amostragem única para cada tratamento, retirada da mistura do leite dos dois animais. Depois de acondicionadas em sacos plásticos identificados, as amostras foram tratadas por processo térmico de pasteurização lenta a $65^{\circ} \mathrm{C}$ por 30 minutos (Brasil, 2000) e finalmente congeladas a $-4^{\circ} \mathrm{C}$.

As análises físico-químicas foram realizadas no Laboratório de Bromatologia do Departamento de Nutrição, pertencente à Universidade Federal da Paraíba, e a análise instrumental dos ácidos graxos no Laboratório de Cromatografia Instrumental do Departamento de Engenharia Química, pertencente à Universidade Federal de Pernambuco. Foram determinados os teores de proteína, pelo método MicroKjedahl (métodos AOAC, 991.20 e 991.23); extrato seco total, por secagem até obtenção de peso constante (método AOAC, 925.23) (AOAC, 1998); lipídios, utilizando-se o lactobutirômetro de Gerber (Instituto Adolfo Lutz, 1985); e lactose (em g/100 g), pela redução de Fehling (Instituto Adolfo Lutz, 1985). Determinaram-se ainda o índice de densidade por leitura em termolactodensímetro a $15^{\circ} \mathrm{C}$ (Instituto Adolfo Lutz, 1985) e a acidez, expressa em ${ }^{\circ} \mathrm{D}$ (método AOAC 947.05) (AOAC, 1998).

Para a análise do perfil de ácidos graxos, as amostras foram submetidas à centrifugação a frio para separação da

Tabela 1 - Composição nutricional (\%) dos ingredientes das dietas experimentais

\begin{tabular}{lcccc}
\hline Nutriente & $\begin{array}{c}\text { Farelo } \\
\text { de milho }\end{array}$ & $\begin{array}{c}\text { Farelo } \\
\text { de soja }\end{array}$ & $\begin{array}{c}\text { Farelo } \\
\text { de trigo }\end{array}$ & $\begin{array}{c}\text { Silagem } \\
\text { de maniçoba }\end{array}$ \\
\hline MS $^{2}$ & 89,16 & 89,66 & 88,88 & 28,50 \\
MO $^{2}$ & 96,85 & 93,62 & 93,64 & 93,82 \\
MM $^{2}$ & 3,15 & 6,38 & 6,36 & 6,17 \\
PB $^{2}$ & 11,08 & 48,92 & 15,08 & 14,43 \\
EE $^{2}$ & 10,86 & 2,06 & 2,47 & 9,96 \\
FDN $^{2}$ & 28,48 & 15,50 & 47,54 & 50,21 \\
FDA $^{2}$ & 6,88 & 10,04 & 17,08 & 36,40 \\
Lignina $^{2}$ & 2,85 & 2,48 & 5,83 & 7,50 \\
CT $^{2}$ & 74,91 & 42,92 & 76,06 & 69,44 \\
CNF & 46,43 & 27,14 & 28,53 & 19,23 \\
PIDN $^{2}$ & 3,39 & 5,28 & 4,5 & 2,96 \\
PIDA $^{2}$ & 0,79 & 2,25 & 0,69 & 1,17 \\
\hline
\end{tabular}

1 Subproduto da fabricação de flocos de milho.

$2 \%$ da matéria seca. gordura dos demais nutrientes. Destas amostras, retiraram-se alíquotas de $2 \mathrm{~g}$ para os processos de extração (Folch et al., 1957), saponificação e esterificação. Após a extração, realizou-se a metilação conforme descrito por Hartman \& Lago (1973).

O painel sensorial foi formado por oito provadores, de ambos os sexos, entre alunos, funcionários e professores da instituição com idade entre 20 e 45 anos. Aplicou-se um questionário para avaliação da saúde, da afinidade ao produto, da disponibilidade de tempo, do interesse e da capacidade de empregar os termos descritivos. Também foram aplicados os testes de identificação aos quatro sabores básicos utilizando-se soluções de sacarose (2\%), ácido cítrico $(0,07 \%)$, cloreto de sódio $(0,2 \%)$ e ácido tânico $(0,07 \%)$ e o teste triangular para comparação dos leites caprino e bovino.

Para a Análise Descritiva Quantitativa (ADQ), seguindo metodologia simplificada sugerida por Faria \& Yatsuyanagi (2002), foi elaborada uma ficha com os termos e atributos discutidos pela equipe de provadores treinada. Utilizou-se uma escala não-estruturada, com uma linha contínua de 9 cm de comprimento, ancorada nas extremidades com termos que expressavam o mínimo e o máximo da característica de qualidade a ser julgada. Em seguida, estes valores foram

Tabela 2 - Composição das dietas experimentais (\%MS)

\begin{tabular}{|c|c|c|c|c|}
\hline \multirow[t]{2}{*}{ Item } & \multicolumn{4}{|c|}{ Relação volumoso:concentrado } \\
\hline & $30: 70$ & $40: 60$ & $50: 50$ & $60: 40$ \\
\hline \multicolumn{5}{|l|}{ Ingrediente (\%) } \\
\hline Silagem de maniçoba & 30,00 & 39,99 & 50,00 & 60,00 \\
\hline Farelo de milho & 48,50 & 42,79 & 36,90 & 30,99 \\
\hline Farelo de trigo & 14,00 & 11,01 & 8,00 & 4,99 \\
\hline Farelo de soja & 5,50 & 4,20 & 3,09 & 1,99 \\
\hline Calcário & 1,00 & 1,01 & 1,01 & 1,01 \\
\hline Suplemento mineral & 1,00 & 1,01 & 1,01 & 1,01 \\
\hline \multicolumn{5}{|c|}{ Composição nutricional } \\
\hline MS & 54,47 & 48,21 & 43,23 & 39,18 \\
\hline MO & 48,66 & 41,88 & 36,52 & 32,62 \\
\hline MM & 5,81 & 6,33 & 6,72 & 6,92 \\
\hline PB & 14,50 & 14,23 & 14,02 & 13,83 \\
\hline $\mathrm{EE}$ & 8,71 & 8,99 & 9,25 & 9,51 \\
\hline FDN & 36,38 & 38,15 & 39,89 & 41,63 \\
\hline FDA & 17,20 & 19,80 & 22,42 & 25,02 \\
\hline Lignina & 4,58 & 4,96 & 5,34 & 5,72 \\
\hline $\mathrm{CT}$ & 70,16 & 69,99 & 69,77 & 69,52 \\
\hline CNF & 33,87 & 31,92 & 29,94 & 27,95 \\
\hline PIDN & 3,45 & 3,35 & 3,25 & 3,16 \\
\hline PIDA & 0,95 & 0,98 & 1,00 & 1,03 \\
\hline EM $(\text { Mcal/kg DM })^{1}$ & 2,71 & 2,60 & 2,49 & 2,37 \\
\hline $\mathrm{Ca}$ & 0,79 & 0,82 & 0,84 & 0,87 \\
\hline $\mathrm{P}$ & 0,53 & 0,49 & 0,45 & 0,40 \\
\hline
\end{tabular}


convertidos em uma escala de notas que variaram de 0 a 9 pontos antes das análises estatísticas.

Cada julgador recebeu quatro amostras de leite correspondentes às dietas com 30, 40, 50 e $60 \%$ de níveis de silagem de maniçoba e realizou quatro sessões correspondentes aos quatro períodos de colheita, equivalentes a quatro repetições. O leite foi servido $(50 \mathrm{~mL})$ a $7^{\circ} \mathrm{C}$, em recipientes plásticos tampados e codificados com três dígitos. Entre uma amostra e outra, serviram-se biscoito cream-craker para limpar o palato e água mineral para lavar a boca. Uma ficha com questionário elaborado e um glossário foram fornecidos para se registrar a avaliação.

Os parâmetros químicos e físicos foram submetidos à análise de variância (ANOVA) e regressão pelo seguinte modelo matemático:

$$
Y_{i j k}=\mu+a|q+p| q+q+\text { trat }+ \text { trat } \times q+e_{i j k}
$$

em que: $\mathrm{Y}_{\mathrm{ijk}}=$ observação do animal $\mathrm{i}$ no período $\mathrm{j}$ recebendo o tratamento $\mathrm{k} ; \mu$ = média geral; $\mathrm{a} \mid \mathrm{q}=$ efeito do animal dentro de quadrado; $\mathrm{p} \mid \mathrm{q}$ = efeito do período dentro do quadrado; $\mathrm{q}=$ efeito do quadrado; trat = efeito do tratamento; trat $\times \mathrm{q}=$ efeito da interação tratamento $\times$ quadrado; $\mathrm{e}_{\mathrm{ijk}}=$ erro aleatório associado a cada observação.

As análises de ácidos graxos e características sensoriais foram submetidas à análise de variância (ANOVA) e regressão utilizando-se o seguinte modelo matemático:

$$
\mathrm{Y}_{\mathrm{ij}}=\mu+\text { Per }_{\mathrm{i}}+\text { trat }_{\mathrm{j}}+\mathrm{e}_{\mathrm{ij}}
$$

em que: $Y_{i j}=$ observação do animal no período i recebendo o tratamento j; $\mu$ = média geral; $\operatorname{Per}_{\mathrm{i}}=$ efeito do período; trat. $\mathrm{j}$ = efeito do tratamento; $\mathrm{e}_{\mathrm{ij}}=$ erro aleatório associado a cada observação.

\section{Resultados e Discussão}

Os níveis de silagem utilizados na dieta não promoveram mudanças quantitativas $(\mathrm{P}>0,05)$ nas propriedades químicas e físicas do leite (Tabela 3). Estudando a composição do leite de cabras Saanen durante o período de lactação, Chornobai (1998) e Queiroga (2004) encontraram valores médios semelhantes, de 3,8 e 3,4\% de gordura, 3,3 e 2,7\% de proteína e 12,4 e 11,4\% de extrato seco, respectivamente. As médias encontradas no leite de animais com genótipo nativo foram superiores aos da raça Saanen, considerada especializada para produção de leite mas caracterizada por produzir elevada quantidade de leite com baixo teor de gordura. Os valores encontrados nesta pesquisa, de 3,83 a 4,18\% para gordura e 3,72 a 3,91\% para proteína são relativamente superiores aos encontrados por Soryal et al. (2004), que observaram variação de 2,38 a 3,72\% nos teores de gordura e de 2,26 a 3,35\% nos de proteína ao fornecerem diferentes níveis de suplementação com concentrado a cabras Alpinas.

O valor médio de proteína determinado (3,79 \%) foi semelhante aos reportados por Dantas (1999), que obteve teores de 3,59; 3,79 e 3,61 para cabras 1/2 Pardo-Alpinas, 1/2 Toggenburg e Sem Raça Definida (SRD), respectivamente. Calderon et al. (1993) também não observaram efeito das dietas com alto e baixo nível de concentrado no teor de proteína. Esses resultados são similares aos reportados por Goetsch et al. (2001), que ressaltaram que, mesmo aumentando a quantidade de proteína na ração dos animais, a porcentagem protéica se manteve constante.

A concentração de gordura do leite, segundo González et al. (2001), é susceptível a oscilações, em razão de vários fatores, como raça, turno de ordenha, período de lactação e dieta. O valor obtido neste estudo para a dieta com nível mais alto de concentrado (3,96\%) foi superior aos registrados por Calderon et al. (1993) e Soryal et al. (2004), que reportaram teores de 3,0 e 3,5\%, respectivamente, para dieta com proporção de concentrado equivalente. Alguns autores citam valores de lipídios superiores. Dantas (1999), pesquisando a influência do grau de mestiçagem, relatou valores de 4,23 e 4,25\% para amostras de leite de cabras da raça Pardo-Alpina $1 / 2$ e SRD (Sem Raça Definida), respectivamente. Prasad \& Sengar (2002) encontrou teores de 5,1; 4,8; 5,0 e 5,6\% de gordura para o leite das raças Barbari, Barbari $\times$ Jamunapari, Barbari × Beetal e Barbari × Black Bengal.

A lactose é um dos nutrientes mais estáveis da composição química do leite e está diretamente relacionada à regulação da pressão osmótica (González et al., 2001). O teor de lactose do leite neste estudo não teve variação entre as dietas, o que contraria os resultados descritos por Soryal

\begin{tabular}{|c|c|c|c|c|c|c|}
\hline Característica & \multicolumn{4}{|c|}{ Relação volumoso:concentrado } & Média & CV (\%) \\
\hline Proteína (\%) & $3,72 \pm 0,33$ & $3,72 \pm 0,43$ & $3,91 \pm 0,27$ & $3,80 \pm 0,69$ & 3,79 & 9,43 \\
\hline Lactose (\%) & $4,72 \pm 0,16$ & $4,61 \pm 0,16$ & $4,64 \pm 0,19$ & $4,68 \pm 0,20$ & 4,66 & 3,86 \\
\hline Extrato seco total (\%) & $13,06 \pm 1,09$ & $12,82 \pm 0,92$ & $13,43 \pm 0,90$ & $13,18 \pm 1,20$ & 13,12 & 4,64 \\
\hline Densidade $\left(\mathrm{g} / \mathrm{cm}^{3}\right)$ & $1,032 \pm 0,00$ & $1,032 \pm 0,00$ & $1,033 \pm 0,00$ & $1,034 \pm 0,00$ & 1,033 & 0,13 \\
\hline
\end{tabular}

Tabela 3 - Características do leite de cabras da raça Moxotó alimentadas com dietas com silagem de maniçoba 
et al. (2004), que compararam diferentes níveis de concentrado para cabras da raça Alpina e obtiveram menor valor médio de lactose para a dieta sem suplementação (4,01\%), além de maiores teores de gordura (3,51\%), proteína (3,08\%) e sólidos totais $(11,27 \%)$.

O resultado da acidez titulável não diferiu entre os níveis de silagem de maniçoba, mas foi superior ao valor máximo preconizado pela legislação vigente do estado da Paraíba para o leite de cabra, que varia de 13 a $18^{\circ} \mathrm{D}$. Entretanto, como não foram observadas reduções nos teores de lactose, a acidez elevada não foi ocasionada por contaminação microbiana no leite, o que provavelmente pode ser uma característica específica da raça estudada. Esse resultado evidencia a necessidade de mais pesquisas para estudo dos limites estabelecidos pelas legislações, uma vez que nem sempre representam as características do leite produzido pelos rebanhos nacionais.

O conteúdo de extrato seco total (EST) é um índice importante, pois faz parte da exigência de padrões mínimos no leite e influencia o rendimento dos produtos lácteos. Segundo Chornobai (1998), na França, desde 1969, o pagamento do leite e de seus produtos é feito considerando o conteúdo de extrato seco, especificamente gordura e proteína. O valor médio geral encontrado nesta pesquisa foi superior (13,12\%) aos reportados por Soryal et al. (2004), cujos valores médios equivaleram a 12,1 e 10,86\%, respectivamente. Entretanto, Prasad \& Sengar (2002) relataram valores superiores de EST para o leite das raças Barbari (15,0\%).

Apesar de a seleção natural dos caprinos nativos ter ocorrido no sentido negativo da produção, os resultados comprovam a aptidão leiteira da raça Moxotó, uma vez que foram obtidos elevados teores de proteína, gordura e extrato seco. Esses índices revelam a riqueza nutricional do leite e sua importância tecnológica na elaboração de produtos lácteos, como queijos e iogurtes, entre outros.

Foram identificados no leite 12 ácidos graxos: 8 saturados, 2 monoinsaturados e 2 poliinsaturados. Entre os saturados, destacaram-se os ácidos cáprico (C10:0), mirístico (C14:0), palmítico (C16:0) e esteárico (C18:0), todos expressos em área percentual (\%), com valores médios de 7,17;6,88;21,41 e 20,44\%. Entre os monoinsaturados, o maior percentual foi do ácido oléico (C18:1), com 24,33\%, enquanto o linolênico (C18:3) foi encontrado em concentração de 1,42\%. Os ácidos graxos saturados e insaturados perfazem média de 66,26 e $27,76 \%$, respectivamente, em relação ao total.

Foi verificado efeito linear crescente $(\mathrm{P}<0,05)$ dos níveis de silagem de maniçoba nos teores de ácido mirístico - C14:0 (Figura 1). No entanto, os valores detectados foram inferiores aos relatados por Park et al. (2007). Segundo Chilliard et al. (2001b), o aporte de volumoso da dieta aumenta as proporções de acetato e $\alpha$-hidroxibutirato, importantes precursores na síntese dos ácidos graxos de cadeias curta

Tabela 4 - Concentrações de ácidos graxos no leite de cabras Moxotó alimentadas com dietas com silagem de maniçoba

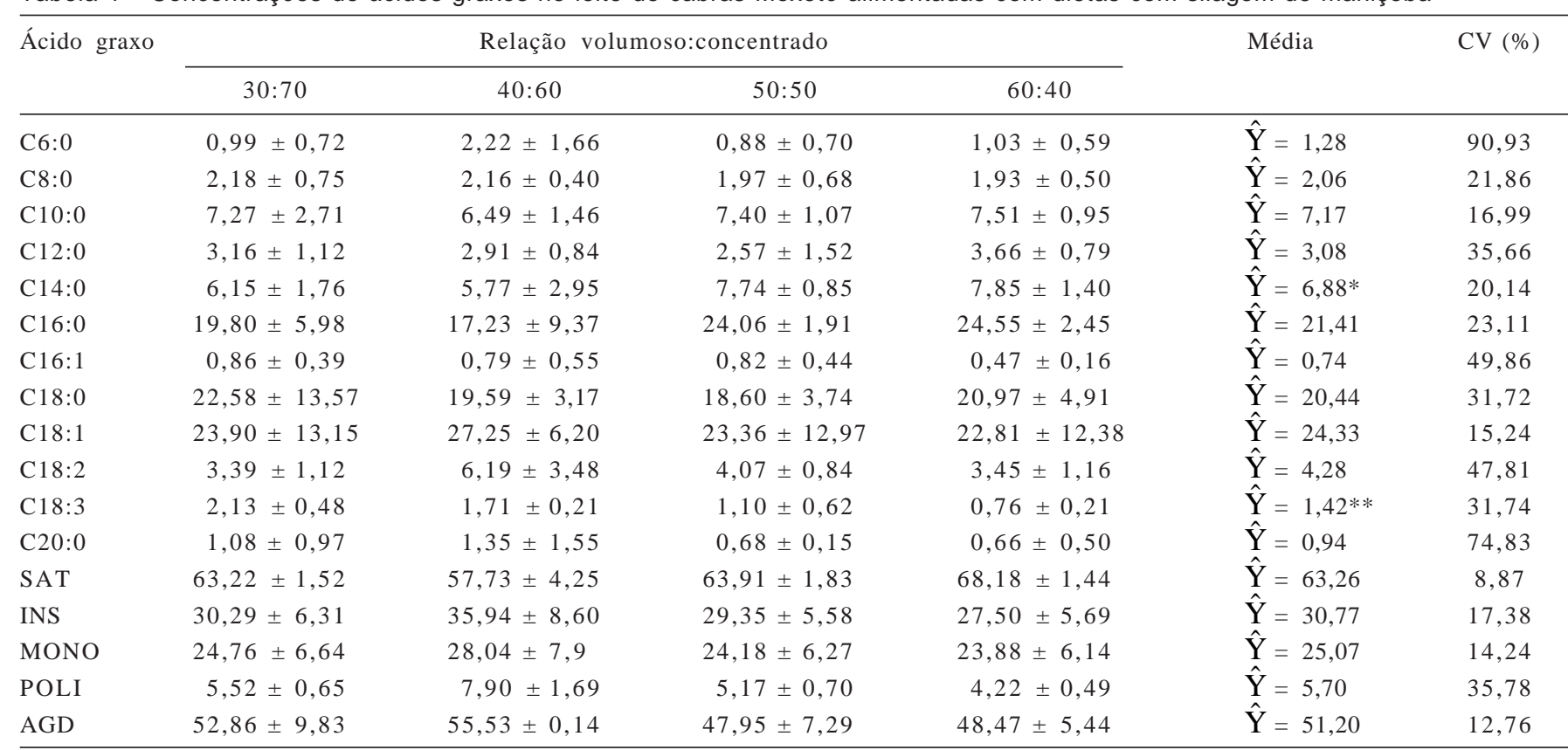

** Significativo a $1 \%$

* Significativo a $5 \%$.

AGD - ácidos graxos desejáveis (insaturados + C18:0). 
e média, o que provavelmente contribuiu para o aumento desse ácido graxo. Entretanto, efeito contrário foi verificado na concentração do ácido linolênico (C18:3) $(\mathrm{P}<0,01)$, que decresceu à medida que aumentou a participação de silagem na dieta (Figura 1).

Os ácidos poliinsaturados não são sintetizados pelos tecidos dos ruminantes e sua concentração no leite depende estritamente das quantidades absorvidas pelo intestino e das quantidades dispensadas no rúmen que não sofreram biohidrogenação. Portanto, o aumento no nível de silagem diminui proporcionalmente os níveis de concentrado e a disponibilidade de ácidos graxos insaturados para serem utilizados pela glândula mamária na síntese de lipídios do leite (Chilliard et al., 2001b; Grummer, 1991).

Segundo Hartman (1993), o ácido esteárico (C18:0) não está relacionado ao aumento de colesterol, pois, quando ingerido, é metabolizado a ácido oléico (C18:1). Os ácidos láurico (C12:0), mirístico (C14:0) e palmítico (C16:0) e os ácidos graxos trans têm sido associados epidemiologicamente a doenças cardiovasculares por induzirem o aumento de colesterol no sangue; por isso, pesquisas têm focado a atenção na diminuição do percentual desses componentes no leite (Chilliard et al., 2001a; Grummer, 1991).

Quantidades dos ácidos mirístico (C14:0) e palmítico (C16:0) superiores às encontradas neste trabalho quando utilizada a dieta com $60 \%$ de silagem de maniçoba foram reportadas por Chilliard et al. (2001a), que registraram 12 a 14\% de ácido mirístico (C14:0) e 30 a 34\% de ácido palmítico (C16:0) no leite de cabras alimentadas com dietas contendo mais de $60 \%$ de silagem de milho. O ideal é que estes teores sejam os menores possíveis, uma vez que esses ácidos graxos induzem o aumento de colesterol no sangue. Esses autores citaram ainda que teores de 6 a $11 \%$ de ácido esteárico (C18:0) e de 18 a 23\% de ácido oléico (C18:1) são nutricionalmente desejáveis. A utilização de silagem de maniçoba neste trabalho promoveu aumento significativo do ácido mirístico (C14:0), porém, esses percentuais foram mais adequados que os observados no leite de animais alimentados com silagem de milho, fato importante para o consumidor, uma vez que a redução no consumo de gordura saturada reduz o risco de doenças cardiovasculares (Lima et al., 2000).

As cabras da raça Moxotó apresentaram média de 51,2\% de ácidos graxos desejáveis quando alimentadas com silagem de maniçoba, demonstrando superioridade, do ponto de vista nutricional, em relação às demais. Esse aumento provavelmente se deve aos processos relacionados à biohidrogenação ruminal.

Sampelayo et al. (2007) ressaltaram que interações entre forragem, concentrados e óleos da dieta estão relacionadas a variações na composição da gordura do leite e podem ter importantes implicações em todo o perfil de ácidos graxos. As respostas dos caprinos são diferentes das respostas dos bovinos em muitos aspectos da produção de leite e estão relacionadas ao metabolismo dos lipídios na glândula mamária.

Na literatura pesquisada, grande parte dos trabalhos sobre qualidade do leite caprino foi realizada utilizando-se raças exóticas e/ou mestiças, contudo, são raras as informações sobre a composição química e o perfil de ácidos graxos da gordura do leite de cabras de raças nativas. Acredita-se que os ácidos graxos monoinsautrados, como o oléico, não influenciam os níveis de colesterol, entretanto, há indícios de que os teores desse ácido, resultante dos processos de hidrogenação de óleos vegetais, poderiam induzir hipercolesterolemia (Lima et al., 2000).

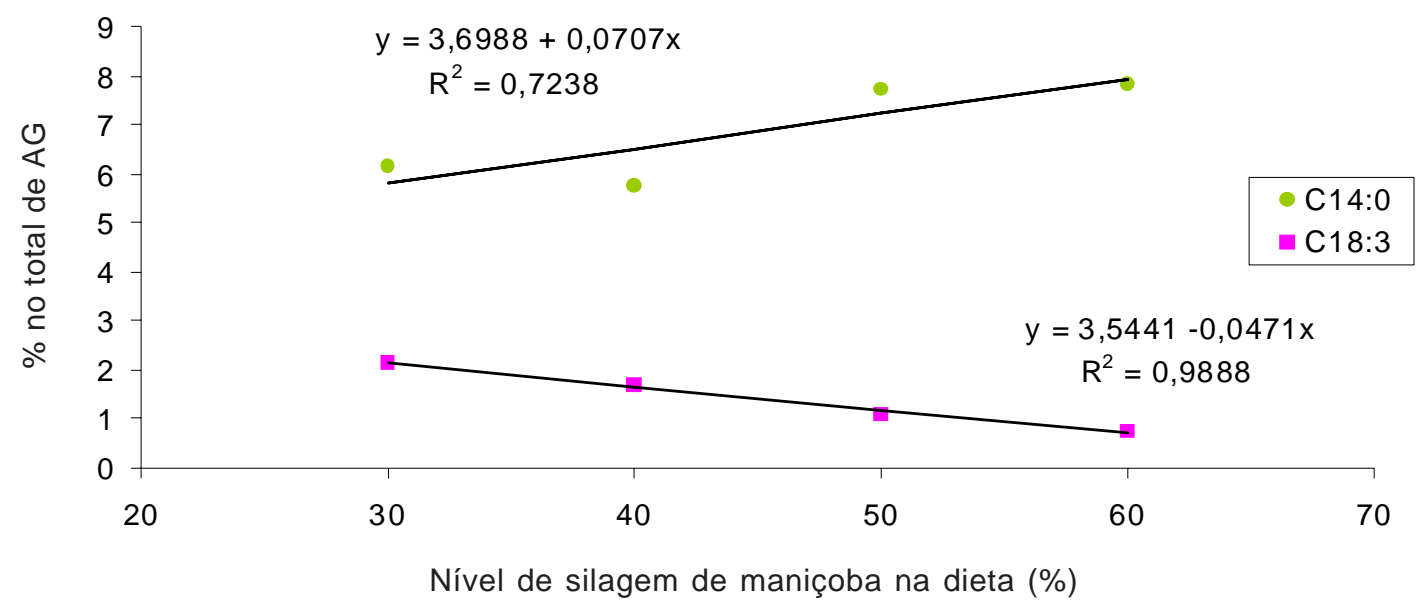

Figura 1 - Concentrações dos AGV C14:0 e C18:3 no leite de cabras alimentadas com dietas com silagem de maniçoba. 
Os ácidos graxos C18:0; C18:1; C18:2 e C18:3, considerados desejáveis do ponto de vista nutricional, foram encontrados em valores médios de 20,44; 24,33; 4,28 e 1,42\% e seus valores não foram afetados $(\mathrm{P}>0,05)$ pelos níveis de silagem de maniçoba, exceto o C18:3, encontrado em maior concentração no leite das cabras alimentadas com a dieta com relação volumoso:concentrado 30:70. Esses valores são superiores aos citados por Alonso et al. (1999), em pesquisa desenvolvida com animais de cinco raças da região da Múrcia-Espanha, na qual obtiveram valores médios de 8,$88 ; 19,3 ; 3,19$ e $0,42 \%$, respectivamente.

Os valores médios encontrados neste trabalho para a composição de ácidos graxos desejáveis foram superiores aos obtidos por Queiroga (2004) em experimento com cabras da raça Saanen em lactação. Em cabras alimentadas com ração completa contendo $50 \%$ de concentrado e $50 \%$ de capim-tifton, esse autor encontrou valores médios de 37,72\% de ácidos graxos desejáveis (C18:0 + insaturados). Do mesmo modo, Chornobai (1998) reportou percentuais inferiores destes ácidos graxos em cabras Saanen em lactação alimentadas com pastagem de grama-estrela africana (Cynodnn lenfuensis), silagem de milho e concentrado: C18:0-13,48;C18:1-23,64;C18:2-1,89eC18:3-0,42 totalizando 41,42 \% de ácidos graxos desejáveis.

As características sensoriais do leite não foram influenciadas $(\mathrm{P}>0,05)$ pelos níveis de silagem de maniçoba (Tabela 5), o que reforça os resultados das análises químicas e físicas do leite (Tabela 3) de que não houve variações nos aspectos sensoriais do leite, do ponto de vista quantitativo, decorrentes dos níveis de silagem de maniçoba.

O leite caprino possui características peculiares de sabor, principal motivo da rejeição pelos consumidores, que resulta na imagem negativa dos produtos. Segundo Calvo \& La Hoz (1992), a formação de compostos voláteis que dão origem ao flavour do leite e dos seus produtos está relacionada à sua composição química.
Pesquisas têm referenciado a gordura como principal nutriente que afeta as características sensoriais do leite (Frost et al., 2001). Jaubert (1996) enfatiza ainda que a atividade da lipase e da lipólise espontânea apresenta maior influência no desenvolvimento do flavour caprino. O leite de cabra é mais suscetível a reações de lipólises principalmente em virtude do elevado percentual de glóbulos de gordura de pequeno tamanho e da maior fragilidade da membrana que os envolvem (Chandan et al., 1992). Nesta pesquisa, os atributos de odor e sabor característico não apresentaram diferença $(\mathrm{P}>0,05)$ relacionada aos níveis de silagem da dieta, provavelmente porque a concentração de gordura também não apresentou diferença significativa (Tabela 3), fato observado também por Oliveira et al. (2005) ao estudarem a influência do fornecimento de palma nos aspectos sensoriais do leite caprino.

Níveis elevados de concentrado diminuem a relação acetato:propionato e comprometem a síntese endógena de ácidos graxos de cadeia curta e média pelas glândulas mamárias, depreciando o teor de gordura no leite (Sampelayo et al., 2007). As proporções de ácidos graxos de cadeia curta, sobretudo o hexanóico, o octanóico e o decanóico, podem intensificar este atributo, contudo, a dieta com maior nível de silagem não propiciou maior produção destes componentes e o menor nível de silagem não inibiu sua produção, portanto, a relação volumoso:concentrado não interferiu no conteúdo de gordura e nos aspectos sensoriais relacionados aos ácidos graxos de cadeia curta, o que está de acordo com os resultados da análise do perfil lipídico (Tabela 4).

Estudos realizados por Verdier-Metz et al. (2000) destacam o potencial odorífero de algumas substâncias presentes nas forragens, em especial os terpenos e sesquiterpenos, e sua influência no aroma do leite e dos queijos. Estas moléculas específicas dos vegetais são mais abundantes em algumas espécies, particularmente as dicoliledôneas, presentes em zonas de montanhas. Algumas

Tabela 5 - Características sensoriais do leite de cabras Moxotó alimentadas com dietas com silagem de maniçoba

\begin{tabular}{|c|c|c|c|c|c|}
\hline \multirow[t]{2}{*}{ Atributo* } & \multicolumn{4}{|c|}{ Relação volumoso:concentrado } & \multirow[t]{2}{*}{ Média } \\
\hline & $30: 70$ & $40: 60$ & $50: 50$ & $60: 40$ & \\
\hline \multicolumn{6}{|l|}{ Odor } \\
\hline Ácido & $1,21 \pm 0,22$ & $1,32 \pm 0,30$ & $1,59 \pm 0,30$ & $1,54 \pm 0,28$ & 1,32 \\
\hline Doce & $2,83 \pm 0,38$ & $2,93 \pm 0,37$ & $2,69 \pm 0,36$ & $2,64 \pm 0,36$ & 2,64 \\
\hline Aparência global & $5,42 \pm 0,43$ & $5,58 \pm 0,38$ & $4,87 \pm 0,51$ & $5,29 \pm 0,42$ & 5,29 \\
\hline
\end{tabular}

* $(P>0,05)$. 
espécies de crucíferas, quando consumidas em grande quantidade, passam para o leite odor acentuado de mato (Urbach, 1990; Badings, 1991). A carência de estudos sobre os compostos voláteis do leite sob influência de forragens nativas e seus possíveis efeitos dificultam a elucidação da utilização destas fontes alimentares na dieta.

Os atributos sabor doce e ácido não foram influenciados pelos níveis de silagem de maniçoba da dieta $(\mathrm{P}>0,05)$. Contudo, o tipo de fermentação produzida implica diretamente na formação de compostos aromáticos, que podem ser incorporados ao leite a partir da absorção direta pelo trato digestivo e ocasionar mudanças bioquímicas (Urbach, 1990). De acordo com os resultados deste estudo, o atributo de sabor de forragem/erva não foi influenciado pelos níveis de silagem de maniçoba $(\mathrm{P}>0,05)$. Os dados obtidos podem indicar que a espécie botânica estudada, conservada na forma de ensilagem, não promoveu no leite mudanças sensoriais perceptíveis.

Os escores atribuídos à aparência global da amostra, apesar de não terem sido influenciados pelos níveis de silagem, indicam que o leite teve boa aceitação, pois, dentro da escala (1 a 9), sua média $(5,29)$ situou-se na faixa intermediária. Não foi verificada influência da participação de níveis de silagem da dieta sobre o atributo odor rançoso, o que demonstra a estabilidade do leite quanto a reações de oxidações autocatalíticas.

Entre os atributos estudados, o odor e o sabor característico caprino apresentaram as maiores médias (2,60 e 3,09 , respectivamente), no entanto, os valores foram pouco representativos e, dentro da escala (1 à 9), remetem à uma intensidade moderada, justificada pela presença de níveis baixos de ácidos graxos de cadeia curta (Tabela 4). Concentrações superiores destes ácidos graxos foram reportadas por Queiroga (2004), que observou durante o período de

Tabela 6 - Componentes principais dos atributos sensoriais do leite de cabras Moxotó alimentadas com dietas com silagem de maniçoba

\begin{tabular}{|c|c|c|c|}
\hline \multirow[t]{2}{*}{ Atributo } & \multicolumn{3}{|c|}{ Componente principal (CP) } \\
\hline & CP 1 & CP2 & СР 3 \\
\hline $\begin{array}{l}\text { Variação total explicada (\%) } \\
\text { Odor }\end{array}$ & 45,66 & 21,57 & 16,28 \\
\hline $\begin{array}{l}\text { Odor característico caprino } \\
\text { Sabor }\end{array}$ & 0,46 & $-0,36$ & $-0,36$ \\
\hline Sabor ácido & 0,36 & 0,56 & $-0,07$ \\
\hline Sabor doce & 0,49 & $-0,06$ & 0,27 \\
\hline Sabor característico caprino & 0,46 & $-0,35$ & $-0,28$ \\
\hline Sabor forragem/erva & 0,30 & $-0,13$ & $-0,07$ \\
\hline Aparência global & 0,32 & 0,77 & 0,54 \\
\hline
\end{tabular}

lactação variações na composição lipídica do leite e influência destes compostos na aceitabilidade do leite de cabra.

$\mathrm{Na}$ análise dos componentes principais (CP) da ADQ, foram expressos os percentuais para os três primeiros componentes principais (Tabela 6), que corresponderam a $83,51 \%$ da variação entre as amostras. O CP1 explicou 45,66\% da variação entre as dietas e teve contribuição de todos os atributos. Na formação do CP2, as variáveis que tiveram maior importância foram o odor, o sabor característico caprino, o sabor ácido e a aparência global. No CP3, participaram expressivamente apenas dois caracteres sensoriais: odor característico caprino e aparência global.

\section{Conclusões}

A silagem de maniçoba pode ser incluída em dietas para cabras Moxotó em lactação, pois, em níveis de até $60 \%$ da matéria seca total, não altera a composição e as características sensoriais do leite. $\mathrm{O}$ aporte de silagem na dieta não influencia o teor lipídico do leite, contudo, aumenta na gordura do leite os teores de ácidos graxos desejáveis (C18:0 + insaturados), considerados nutricionalmente importantes pelos seus benefícios à saúde humana.

\section{Literatura Citada}

AGRICULTURAL AND FOOD RESEARCH COUNCIL - AFRC. The nutrition of goats. Wallingford: $C A B$ International, 1998. p.91-97.

ALONSO, L.; FONTECHA, J.; LOZADA, L. et al. Fatty acid composition of caprine milk: major, branched-chain, and trans fatty acids. Journal of Dairy Science, v.82, p.878-884, 1999.

ASSOCIATION OF OFFICIAL ANALYTICAL CHEMISTS - AOAC. Official methods of analysis. 16.ed. 4.rev. Washington: 1998. 2v. 1018p.

BADINGS, H. T. Milk: volatile compounds in foods and beverages. New York: Marcel Dekker, 1991. p.91-105.

BRASIL. Ministério da Agricultura. Secretaria Nacional de Agricultura. Instrução Normativa $n^{\circ} 37$, de 8 de novembro de 2000. Regulamento Técnico de Produção, identidade e qualidade do leite de cabra. Diário Oficial da União. Disponível em: www.Agricultura.gov.brldas\dipoallegislacaoespecifica_leited.htm. Acesso em: 13/5/2003

CALDERON, I.; De PETERS, E.J.; SMITH, N.E. et al. Composition of goat's milk: changes within milking and effects of a high concentrate diet. Journal of Dairy Science, v.76, p.17531771, 1993.

CALVO, M.M.; LA HOZ, L. Flavour of heated milks. A review. International Dairy Journal, v.2, p.69-81, 1992.

CHANDAN, R.C.; ATTAIE, R.; SAHANI, K.M. Nutritional aspects of goat milk and its products. In: INTERNATIONAL CONFERENCE IN GOAT'S, 5., New Dehli, 1992. Proceedings... New Dehli: 1992. p.1869-1890.

CHILLIARD, Y.; FERLAY, A.; DOREAU, M. Effect of different types of forages, animal fat or marine oils in cow's diet on milk fat secretion and composition, especially conjugated linoleic acid (CLA) and polyunsaturated fatty acids. Livestock Production Science, v.70, p.31-48. 2001a. 
CHILLIARD, Y.; FERLAY, A.; DOREAU, M. Contrôle de la qualité nutritionnelle des matières grasses du lait par l'alimentation des vaches laitières: acides gras trans, polyinsaturés, acide linoléique conjugué. INRA Productions Animales, v.14, p.323335, 2001b.

CHORNOBAI, C.A.M. Caracterização fisico-química de leite in natura de cabras cruza Saanen, ao longo do período de lactação: Maringá: Universidade Estadual de Maringá, 1998. 100p. Dissertação (Mestrado em Química) - Universidade Estadual de Maringá, 1998.

COULON, J.B.; PRIOLO, A. La qualité sensorielle des produits laitiers et de la viande dépend des fourrages consommés par les animaux. INRA Productions Animales, v.15, n.5, p.333-342, 2002.

DANTAS, A.H.G. Influência do grau de mestiçagem sobre a composição química do leite de cabra. João Pessoa: Universidade Federal da Paraíba, 1999. 80p. Dissertação (Mestrado em Nutrição) - Universidade Federal da Paraíba, 1999.

FARIA, E.V.; YATSUYANAGI, K. Técnicas de análise sensorial. Campinas: ITAL/LAFISE, 2002. 116p.

FOLCH, J.; LEES, M.; STANLEY, G.H. et al. A simple method for isolate and purification of total lipid from animal tissues. Journal Biological Chemistry, v.226, p.497-509, 1957.

FROST, M.B.; DIJKSTERHUIS, G.; MARTENS, M. Sensory perception of fat in milk. Food Quality and Preference, v.12, p.327-336, 2001.

GOETSCH, A.L.; DETWEILER, G.; SALHU, T. et al. Dairy goat performance with different dietary concentrate levels in late lactation. Small Ruminant Research, v.41, p.117-125, 2001.

GONZÁLEZ, F.H.D.; DURR, J.W.; FONTANELLI, R. Uso de leite para monitorar a nutrição e metabolismo de vacas leiteiras. Porto Alegre, 2001. 72p.

GRUMMER, R.R. Effect of feed on the composition on milk fat. Journal Dairy Science, v.74, p.3244-3257, 1991.

HAENLEIN, G.F.W. Goat milk in human nutrition. Small Ruminant Research, v.51, n.1, p.155-63, 2004.

HARTMAN, L. A evolução de idéias sobre a função dos óleos e gorduras na alimentação humana. Boletim SBCTA, v.27, p.5558, 1993.

HARTMAN, L.; LAGO, B.C.A. Rapid preparation of methyl esters from lipids. Laboratory Practice, v.22, p.475-477, 1973.

INSTITUTO ADOLFO LUTZ - IAL. Normas analíticas do Instituto Adolfo Lutz. 3.ed. São Paulo: 1985. v.1, 533p.

JAUBERT, J.P.; BODIN, J.P.; JAUBERT, A. Flavour of goat farm bulk milk. In: MORAND-FEHR, P. (Ed.) Recent advances in goats research. Zaragoza: CIHEAM-IAMZ, 1997. 93p. (Cahiers Options Mediterrannés, 25).
NATIONAL RESEARCH COUNCIL - NRC. Nutrient requirements of dairy cattle. 7.ed. Washington, D.C.: National Academy of Science, 2001. 363p.

LIMA, F.E.L.; MENEZES, T.N.; TAVARES, M.P. et al. Ácidos graxos e doenças cardiovasculares: uma revisão. Revista de Nutrição, v.13, n.2, p.73-80, 2000.

OLIVEIRA, R.S. Características sensoriais do leite de cabras alimentadas com palma forrageira (Opuntia fícus indica Mill.) em substituição parcial ao capim-elefante (Pennisetum purpureum Schum). Areia: Universidade Federal da Paraíba, 2005. 69p. Dissertação (Mestrado em Zootecnia) Universidade Federal da Paraíba, 2005.

PARK, Y.W.; JUAREZ, M.; RAMOS; M. et al. Physico-chemical characteristics of goat and sheep milk. Small Ruminant Research, v.68, p.88-113, 2007.

PRASAD, H.; SENGAR, O.P.S. Milk yield and composition of the Barbari gota breed and its cross with Jamunapari, Beetal and Black Bengal. Small Ruminant Research, v.45, p.79-83, 2002.

QUEIROGA, R.C.R.E. Caracterização nutricional, microbiológica, sensorial e aromática do leite de cabras Saanen, em função do manejo do rebanho, higiene da ordenha e fase de lactação. Recife: Universidade Federal de Pernambuco, 2004. 148p. Tese (Doutorado em Zootecnia) Universidade Federal de Pernambuco, 2004.

SAMPELAYO, S.; CHILLIARD, Y.; SCHMIDELY, P. et al. Influence of type of diet on the fat constituents of goat and sheep milk. Small Ruminant Research, v.68, p.42-63, 2007.

SILVA, D.S.; MEDEIROS, A.N. Eficiência do uso dos recursos da Caatinga: produção e conservação. In: SIMPÓSIO INTERNACIONAL DE CAPRINOS DE CORTE, 2., SIMPÓSIO INTERNACIONAL SOBRE O AGRONEGÓCIO DA CAPRINOCUltURA LEITEIRA, 1., 2003, João Pessoa. Anais... João Pessoa: 2003. p.571-582.

SILVA, D.J.; QUEIROZ, A.C. Análise de alimentos: métodos químicos e biológicos. 3.ed. Viçosa, MG: Editora UFV, 2002. 235p.

SNIFFEN, C.J.; O'CONNOR, J.D.; Van SOEST, P.J. et al. A net carbohydrate and protein availability. Journal of Animal Science, v.70, p.3562-3577, 1992.

SORYAL, K.A.; ZENG,S.S.; MIN, B.R. et al. Effect of feeding systems on concentrate of goat milk e yield of Domiati cheese. Small Ruminant Research, v.54, p.121-129, 2004.

URBACH, G. Effect of feed on flavor in dairy foods. Journal of Dairy Science, v.73, p.3639-3650, 1990.

VERDIER-METZ, I.; COULON, J.B.; VIALLON, C. et al. Effet de la conservation du fourrage sur les caractéristiques physicochimiques et sensorielles des fromages. In: RENCONTRES SUR LES RECHERCHES AUTOR DES RUMINANTS, 7., 2000, Paris. Proceedings... Paris: 2000. 318p. 